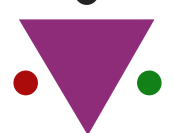

IJCRR

Section: Healthcare

Sci. Journal Impact

Factor: $6.1(2018)$

ICV: 90.90 (2018)

(c) (i) (9)

Copyright@IJCRR

\title{
Perceived Maternal Needs and Priorities in Neonatal Intensive Care Environment
}

\section{Pushpa Thomas John ${ }^{1}$, Sneha Pitre ${ }^{2}$, Shukri Adam ${ }^{3}$}

'RN, NICU AOWCH, UAE; 'Associate professor RAKMHSU College of Nursing Ras Al Khaimah UAE; ${ }^{2}$ Assistant Dean (Clinical) RAKMHSU College of Nursing Ras Al Khaimah UAE.

\section{ABSTRACT}

Background: Hospitalization of the neonate is very stressful and challenging for mothers as they have to adapt to their own physiological and psychological changes along with the unexpected needs of the baby. If these needs are not identified and taken care off can lead to suboptimal health and developmental outcomes for the infant.

Purpose: To assess the maternal needs and priorities of the hospitalized neonate in NICU.

Methods: A cross-sectional survey was conducted among 61 mothers of hospitalized neonates with the use of maternal needs inventory. Needs were categorized into five deduced dimensions Assurance, proximity, Information, support and comfort. Besides, Mothers were asked to enlist five most important needs as per the priority from high to low.

Results: Out of 25 listed needs, Assurance needs were reported as most important and comfort needs as a least. In priority, all five needs were related to the health of the baby than the mother's comfort. Significant association between maternal needs and selected demographic variables were observed in the study.

Conclusion: Maternal need inventory is a simple yet effective tool for identifying the needs of mothers which is vital for promoting family-centred care based on dignity and respect; information sharing; participation; and collaboration.

Key Words: Maternal needs, Priorities, Mothers, NICU

\section{INTRODUCTION}

Birth of a baby is a complex process. It is a time for mother and baby to adapt to many physiological and psychological changes. During this period women are vulnerable to health problems directly related to childbirth and compromised selfcare especially when the baby requires admission in special care unit like NICU. According to the World Health Organization (WHO), every year an estimated 15 million babies are born preterm $(<37$ weeks of gestation) and this global trend is rising. ${ }^{1}$ It is also observed that one in every eight infants requires admission to a neonatal unit, with the most common reasons being low birth weight and prematurity. Survival of these babies have been improved due to advancement in technology but still, need to improve on fulfilling the psychological needs of both mother and baby. Hospitalization of neonate interrupts and delays parent-infant bonding and attachment. Therefore, mothers experience anxiety and mental anguish with each specific situation regarding the vulnerable state of the infant's health. ${ }^{2}$

Stress associated with hospitalization of the neonate in NICU has many implications on the health of mother and baby. It interferes with the development of bonding and attachment which further can lead to postpartum depression, anxiety and post-traumatic disorder in mother. It also affects the production of breast milk which is vital for the development of the baby. ${ }^{3}$ In addition to this common stressor experienced by parents include anxiety about their infant's well being, struggle to meet the needs of other siblings at home, loss of parenting role and financial burden. Therefore NICU experiences are becoming a critical area of the study. ${ }^{4}$

Other factors such as maternal depression and anxiety have been linked to lowered capacity for decision-making and infant care as well as poor physiological and psychological outcomes for infants that may last through adolescence. The

\section{Corresponding Author:}

Pushpa Thomas John, RN, NICU AQWCH UAE.

ISSN: 2231-2196 (Print)

Received: 14.07 .2020
ISSN: $0975-5241$ (Online)

Revised: 08.09 .2020
Accepted: 18.10 .2020
Published: 24.11 .2020 
relationship between the mental health of mother and infant well-being further highlights the importance of identifying needs, risk and protective factors for mothers whose infants are admitted to the NICU. ${ }^{5}$

Communication plays an important role in minimizing the stress and anxiety among parents of neonates admitted in NICU. Because of reducing anxiety and stress, there is necessary to identify the exact needs of the parents. Many researchers have tried to identify these needs because of making their experience tolerable and less traumatic. ${ }^{6}$ This need was also felt by the investigator while working in NICU which will help in ensuring family centred care. Therefore in the present study needs and priorities of mothers of hospitalized neonate were assessed with the use of maternal needs inventory. We aimed to assess the needs and priorities of mothers whose neonates are admitted in NICU and to find the association between the maternal needs and selected demographic variables.

\section{MATERIAL AND METHODS}

Cross-sectional descriptive survey design was used in the study.

\section{Participants}

Participants for the study were mothers of neonates admitted in Neonatal intensive care unit of the hospital which comes under the Ministry of health and prevention U A E. This hospital specifically caters to the needs of Mother and child. All mothers fulfilling inclusion criteria and gave informed consent to participate in the study. Total of Sixty one mothers completed the survey.

\section{Data collection tool and technique}

Self-reported maternal needs inventory was used to assess the maternal needs of hospitalized neonate. It included 26 items related to various maternal needs. These needs were identified on the basis of review of literature and investigator's self-experience while working as a health care professional in NICU. The mothers were told to rate the needs as most important to not important with a scoring of 1 to 4 . It was scored as 1 for not important, 2 for least important, 3 for important and 4 for most important. These needs were categorized into five dimensions Assurance, Information, Proximity, Support and Comfort. All mothers were also told to list five most important needs as per the priority.

\section{Procedure for data collections}

Data was collected from prospective participants who gave consent for their participation in the study. Demographic data was collected from mother and electronic medical records. Need were assessed by using self-reported maternal needs inventory. Approximately 40 to 45 minutes were taken by each mother to complete the inventory. Privacy and confidentiality were maintained by investigator related to the information given by participants.

\section{RESULTS}

\section{Demographic Characteristics}

Sixty-one mothers participated in the study. Majority of mothers $(73.8 \%)$ were multipara with no history $(77 \%)$ of previous experience of hospitalization for their neonates in critical care area like NICU and were Emiratis. Concerning demographic characteristics of neonates, $57.4 \%$ were full-term having normal $(\geq 2.5 \mathrm{Kg})$ birth weight. Percentage $(57.4 \%)$ of female neonates has shown dominance in the study. It is also observed that the almost equal number of babies were born either via normal $(50.8 \%)$ or cesarean route $(49.2 \%)$. Common reasons observed for admission to NICU were prematurity $(34.4 \%)$, neonatal jaundice $(26.2 \%)$ and Respiratory distress syndrome (16.4\%)( Table 1).

\begin{tabular}{lcccc}
\multicolumn{4}{l}{ Table 1: Maternal Needs As } & Per The Categories \\
\hline Assurance & f & $\%$ & Mean & S.D \\
Proximity & 58 & $95 \%$ & 3.86 & 0.223 \\
Information & 56 & $92 \%$ & 3.72 & 0.244 \\
Support & 54 & $89 \%$ & 3.58 & 0.312 \\
Comfort & 54 & $89 \%$ & 3.58 & 0.324 \\
\hline
\end{tabular}

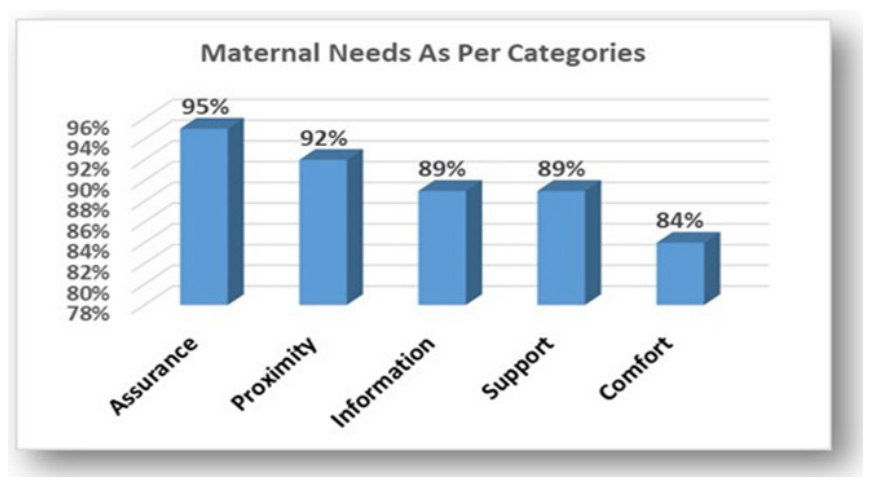

Figure 1: Maternal needs as per the category.

Data presented in Table No. 1 and figure No. 1 indicates the rating of deduced dimensions in the order of their importance expressed by mother through need inventory. Out of four dimensions, Assurance needs were rated as highest $(95 \%)$ followed by proximity (92\%), Information and support $(89 \%)$ and comfort needs $(84 \%)$ respectively. 
Table 2: Five Most Important Needs Expressed by Mothers

\begin{tabular}{lcccc} 
Need (category) & f & $\%$ & Mean & S.D \\
$\begin{array}{l}\text { To be allowed to visit the baby } \\
\text { whenever needed (Proximity) }\end{array}$ & 60 & $98 \%$ & 3.95 & 0.218 \\
$\begin{array}{l}\text { To know why things are done for } \\
\text { my baby ( Assurance ) }\end{array}$ & 59 & $97 \%$ & 3.92 & 0.277 \\
$\begin{array}{l}\text { To know what things are planned } \\
\text { for the baby (Assurance) }\end{array}$ & 58 & $95 \%$ & 3.90 & 0.300 \\
$\begin{array}{l}\text { To be felt respected (Proximity) } \\
\text { To get information on nursing } \\
\text { care every day (Information ) }\end{array}$ & 58 & $95 \%$ & 3.90 & 0.300 \\
\hline
\end{tabular}

As per the data presented in Table 2 majority (98\%) of mothers expressed the need for allowing them to visit the baby whenever they desire. As a natural maternal instinct, another important need expressed by mothers were about receiving appropriate information related to what exactly is done $(97 \%)$ and planned $(95 \%)$ for their babies. Majority of mothers also felt the need of getting respect (93\%) from healthcare professionals.

Table 3: Five Least Important Needs Expressed by Mothers

\begin{tabular}{lcccc}
\hline Need (Category) & f & $\%$ & Mean & S.D. \\
$\begin{array}{l}\text { To know the name of the nurs- } \\
\text { ing personnel taking care of } \\
\text { my child (proximity) }\end{array}$ & 51 & $84 \%$ & 3.36 & 0.606 \\
$\begin{array}{l}\text { To know approximate ex- } \\
\text { penditure for the NICU stay } \\
\text { (Information) }\end{array}$ & 49 & $80 \%$ & 3.20 & 0.749 \\
$\begin{array}{l}\text { To be called at home about } \\
\text { important changes in my baby's } \\
\text { condition (Information) }\end{array}$ & 48 & $79 \%$ & 3.18 & 0.695 \\
$\begin{array}{l}\text { To have a good food outlet in } \\
\text { the hospital ( Support ) }\end{array}$ & 47 & $77 \%$ & 3.13 & 0.562 \\
$\begin{array}{l}\text { To have good music played all } \\
\text { the time to be in a relaxed state } \\
\text { (Comfort) }\end{array}$ & 40 & $66 \%$ & 2.67 & 1.106 \\
\hline
\end{tabular}

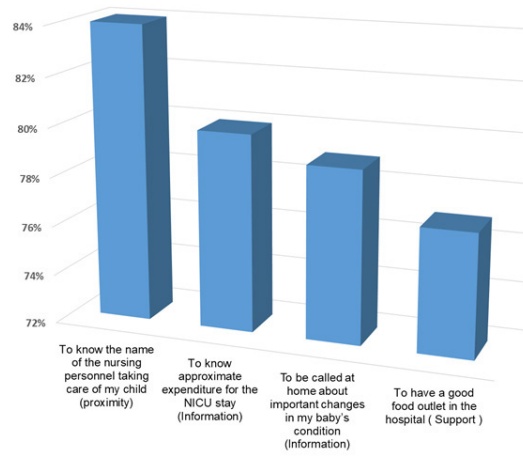

Figure 2: Five Least Important Needs Expressed by Mothers.
As per the data presented in Table No. 3 and figure no. 2 it is evident that mothers were not much concern about their personal needs neither they felt the need of knowing the name of the person who is taking care of their baby (84\%) and to have good food outlet $(77 \%)$. It is also observed that participants were not much keen on knowing the approximate expenditure for the NICU stay ( $80 \%)$. It may be due to the fact money is not a matter of concern than the baby's health for them.

Data presented in Table 4 and figure 3 indicates that the majority of the mothers have given priority to the needs of the baby than their own.

\begin{tabular}{|c|c|c|c|}
\hline Needs & Dimension & $f$ & $\%$ \\
\hline $\begin{array}{l}\text { To know what things are } \\
\text { planned for the baby }\end{array}$ & Assurance & 49 & 80 \\
\hline $\begin{array}{l}\text { To get information on nursing } \\
\text { care every day }\end{array}$ & Information & 48 & 79 \\
\hline $\begin{array}{l}\text { To know the progress of the } \\
\text { baby }\end{array}$ & Assurance & 44 & 72 \\
\hline To meet the doctor every day & Proximity & 42 & 69 \\
\hline $\begin{array}{l}\text { To know the exact condition of } \\
\text { my baby }\end{array}$ & Information & 32 & 52 \\
\hline
\end{tabular}

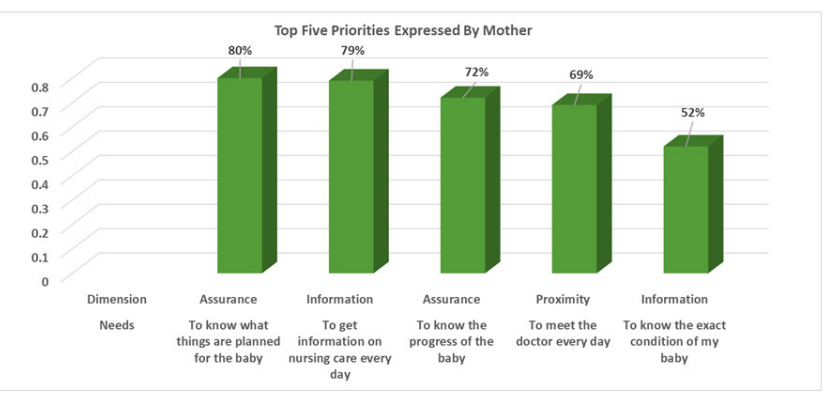

Figure 3: Top Five Priorities Expressed by Mother.

\section{Association between maternal needs and se- lected demographic variables}

In present study significant association was observed between para and need to know the exact condition of the baby $(0.000)$, Nationality and receiving information about the baby (0.002), Number of Birth to the need to have a staff who can communicate in a language which mother understands( $\mathrm{p}$ value 0.003 ), Age of mother to the need to have good music played all the time to be in a relaxed state(p-value 0.022) and Educational qualification of Mother to the need, to meet doctor every day(p-value 0.039 ).

A significant association was also observed between mothers with previous experience of hospitalization of their neonate in NICU with the need to know the exact condition of the baby (p-value 0.046) and type of birth to the need to have 
someone concerned about my health(p-value 0.045$)$ also have shown significant association.

\section{DISCUSSION}

Pregnancy and childbirth are very unique and challenging experience for women. Maternal health during the antenatal and postnatal period is crucial for the well being of both baby and mother. Postnatal period specifically is also associated with many new needs and responsibilities, especially if the baby requires special care in NICU. In such situation acknowledgement of maternal needs becomes an important responsibility of nursing personnel who are involved in the care of these neonates. In the present study it was observed that needs belonging to Assurance category were rated as most important (95\%) followed by proximity (92\%), information (89\%), support (89\%) and comfort (84\%) needs respectively. Needs specified in assurance category were about the concern which every mother has shown towards the health of her child-like "To know why things are done for my baby, what is the plan and to know about the progress of the baby". These findings of the study strongly indicate the innate apprehension of the mothers about their baby's health rather than their comfort.

Concerning proximity needs a majority $(98 \%)$ of mothers expressed the desire to visit their baby whenever they want and to meet the doctor every day to know about the condition of their baby. It may be due to fear of uncertainty associated with the health of her baby and also to ensure baby is receiving appropriate care in NICU. It suggests that mothers should be involved in providing care to the baby whenever possible and receive appropriate information about the condition of the baby. It will indirectly help to reduce stress, enhance confidence and bonding among mothers with their baby.

Respect and acceptance are essential for the development of the therapeutic relationship between health care providers and mothers of hospitalized children. Researchers have observed that patients who perceive they are being treated respectfully may experience improved clinical outcomes and greater satisfaction with their care. ${ }^{7}$ In the present study also need to be respected and accepted from hospital staff was expressed by the majority ( $97 \%$ ) of mothers.

Receiving complete information about the baby's condition, treatment plan and progress is a fundamental right of the parents of the hospitalized neonate. Moreover, it helps to reduce stress. In the present study majority of mothers felt the need to get information about the condition, care provided and also about the equipment which is very scary to look at. This need was also observed in the study where the mother's lived experience of connection with their preterm was assessed. ${ }^{8}$ In yet another study parents' experiences of communication with the neonatal intensive-care unit staff was assessed.
Feeling of dependency on hospital staff for receiving information about their child and loss of parenting was observed when they were not involved in planning and providing care to the child. ${ }^{9}$

Receiving appropriate support during stress is a need of every human being. It was evident from the expression of 95 $\%$ mothers that there should be someone concerned about their health also. Advocacy and preparing parents for taking care of their hospitalized neonate is an important responsibility of the neonatal nurse. It necessitates the availability of staff who can communicate with the parents in the language which they can understand. In Present study, a substantial number of $(90 \%)$ mothers expressed this need "To have a staff who can communicate with us in a language which we understand". It strongly suggests the need for staff who can communicate and give appropriate information to the parents in the language which they understand.

Another important finding of the present study is about the needs related to comfort which was rated as least important as compared to other needs with the main focus on the care of their babies. But in reality, during the puerperal period, every aspect of women's life is disrupted as she needs to adjust to her physical, physiological and psychological needs, routines and relationships. However, most of the time attention is given to the needs of the newborn. Many researchers have revealed the consequences of neglected needs of the mother during puerperium. In one of the research, it was observed that almost one-third of mothers expressed their inability for some time to take care of their babies during the initial two months of puperium. The reason was the alteration in their physical or emotional health during this period. $42 \%$ of all mothers reported physical and /or emotional impairment. ${ }^{10}$ In yet another study unmitigated fatigue and sleep disruption during the postpartum period has shown an association with multiple morbidities, including post partum depression which can further lead to disruption in transition to parenting and compromised outcome for the infant and other members of the family. ${ }^{11}$ Mothers in the present study also are at risk of developing these problems if their needs are neglected. It alerts the nursing personnel to pay equal attention to the personal needs of mothers. As it is observed that nurses who are sensitive to the needs of mothers help guide and strengthen maternal responses to their infants, thus promoting attachment. ${ }^{12}$

Findings of the present study are also consistent where the needs of parents of preterm neonates admitted in NICU were assessed by using the modified version of Family needs inventory. It was observed that these parents also ranked the needs for assurance, proximity, and information as the most important whereas comfort and support needs were ranked as the least important. Needs belonging to assurance had shown predominance as Majority (86\%) of mothers felt the 
need to know about the pain management and expected outcome $(83 \%)$ of their baby. Concern about the handling of the baby was also expressed by $83 \%$ mothers. ${ }^{13}$ It is usually observed that after delivery, the baby's health becomes the priority over the self needs among mothers. Present study findings support this assumption as all five needs which were enlisted by the majority of mothers as priority was related to the health of the baby.

In the present study association between maternal needs and selected demographic variables was assessed. A significant association was observed between para and need to know the exact condition of the baby $(\mathrm{P}<0.001)$, Nationality and receiving information about the baby $(\mathrm{P}<0.002)$, Number of Birth to the need to have a staff who can communicate in a language which mother understands $(\mathrm{P}<0.01)$, Age of mother to the need to have good music played all the time to be in a relaxed state $(\mathrm{P}<0.05)$ and educational qualification of mother to the need, to meet doctor every day $(\mathrm{P}<0.05)$.

The significant association between mothers with previous experience of hospitalization of their neonate in NICU with the need to know the exact condition of the baby $(\mathrm{P}<0.05)$ and type of birth to the need to have someone concerned about my health $(\mathrm{P}<0.05)$ also have shown significant association. All these findings strongly suggest that all health care professionals must pay attention to the needs of the mother for the benevolence of the entire family.

Findings of the study specify the significance of identifying maternal needs of hospitalized neonate. Maternal need inventory is simple, easy to administer and useful tool in planning family-centred care for a better outcome. Use of this inventory can be made as a part of the routine at the time of admission where the mother needs more support and guidance in facing challenges related to her own and baby's health. Nursing staff and students should be made aware of the significance of identifying the needs of the mother and the utilization of this tool in planning care based on the actual needs of the mother. The findings of the study indicate the usefulness of the Maternal need inventory. Further research is required to identify the needs of the mother during different situations and timing such as on admission and discharge of the baby.

\section{CONCLUSION}

Maternal need inventory is simple and easy to administer the tool. Findings of the study emphasize the need for therapeutic communication between mother and health care professionals to ensure optimal health for both mother and child.

\section{ACKNOWLEDGMENT}

Authors acknowledge the immense help received from the scholars whose articles are cited and included in references to this manuscript. The authors are also grateful to authors / editors / publishers of all those articles, journals, and books from which the literature for this article has been reviewed and discussed.

\section{Conflict of Interest: Nil}

\section{Source of Funding: Nil}

\section{REFERENCES}

1. Preterm birth - World Health Organization. Available from www.who.int > Newsroom > Fact sheets > Detail Feb 19,2018 .

2. Pitetti K, Smith B, Hsiao R. Application of perceived maternal parenting self-efficacy (PMP SE) questionnaire in a mid-west community medical center NICU in the United States. Neonat Pediatr Med. 2016;1:106.

3. Lean RE, Rogers CE, Paul RA, Gerstein ED. NICU hospitalization: long-term implications on parenting and child behaviors. Cur Treat Options Pediat 2018;4(1):49-69.

4. Mousavi SS, Chaman R, Khosravi A, Mohagheghi P, Mousavi SA, Keramat A. The needs of parents of preterm infants in Iran and a comparison with those in other countries: a systematic review and meta-analysis. Iranian J Pediat 2016;26(5).

5. Feldman R, Rosenthal Z, Eidelman AI. Maternal-preterm skinto-skin contact enhances child physiologic organization and cognitive control across the first 10 years of life. Biol Psychiatry 2014;75(1):56-64.

6. Mundy CA. Assessment of family needs in neonatal intensive care units. Am J Critic Care 2010;19(2):156-63.

7. Beach MC, Sugarman J, Johnson RL, Arbelaez JJ, Duggan PS, Cooper LA. Do patients treated with dignity report higher satisfaction, adherence, and receipt of preventive care?. Ann Family Med 2005; 3(4): 331-8.

8. Ncube RK, Barlow H, Mayers PM. A life uncertain-My baby's vulnerability: Mothers' lived experience of connection with their preterm infants in a Botswana neonatal intensive care unit. $\mathrm{Cu}-$ rationis 2016;39(1):1-9.

9. Wigert H, Blom MD, Bry K. Parents' experiences of communication with neonatal intensive-care unit staff: an interview study. BMC Pediatrics 2014;14(1):1-8.

10. Declercq ER, Sakala C, Corry MP, Applebaum S, Herrlich A. Listening to mothers III: New mothers speak out. New York: Childbirth Connection. 2013 Jun.

11. Dennis CL, Ross L. Relationships among infant sleep patterns, maternal fatigue, and development of depressive symptomatology. Birth 2005;32(3):187-93.

12. Kearvell H, Grant J. Getting connected: How nurses can support mother/infant attachment in the neonatal intensive care unit. Aus J Adv Nursing (Online) 2010;27(3):75.

13. Alsaiari EM, Magarey J, Rasmussen P. An Investigation of the Needs of Saudi Parents of Preterm Infants in the Neonatal Intensive Care Unit. Cureus 2019;11(1). 